OPEN ACCESS

Edited by:

Qian Zhang,

Harbin Engineering University, China

Reviewed by:

Xubo Ma,

North China Electric Power University,

China

Tiejun Zu,

X'an Jiaotong University, China

${ }^{*}$ Correspondence:

Jinsen Xie

jinsen_xie@usc.edu.cn

Tao Yu

yutao29@sina.com

Specialty section:

This article was submitted to

Nuclear Energy,

a section of the journal

Frontiers in Energy Research

Received: 23 June 2021

Accepted: 09 August 2021

Published: 27 August 2021

Citation:

Xu S, Yu T, Xie J, Yao L and LiZ (2021)

Burnable Poison Selection and

Neutronics Analysis of Plate

Fuel Assemblies.

Front. Energy Res. 9:729552.

doi: 10.3389/fenrg.2021.729552

\section{Burnable Poison Selection and Neutronics Analysis of Plate Fuel Assemblies}

\author{
Shikun $X u^{1,2}$, Tao $Y u^{1,2 *}$, Jinsen $X i e^{1,2 *}$, Lei Yao ${ }^{1,2}$ and Zhulun $L i^{1,2}$ \\ ${ }^{1}$ School of Nuclear Science and Technology, University of South China, Hengyang, China, ${ }^{2}$ Hunan Engineering and Technology \\ Research Center for Virtual Nuclear Reactor, University of South China, Hengyang, China
}

Burnable poisons play a critical role in long-life pressurized water reactors. Plate fuel elements have good application prospects in long-life pressurized water reactors. In longlife pressurized water reactors with large initial residual reactivity in the core, a reasonable selection of burnable poisons can suppress the large residual reactivity at beginning of lifetime and can achieve a long burnup depth at end of lifetime. Therefore, the selection of burnable poisons is a crucial factor to be considered in the design of long-life pressurized water reactors. In this study, the selection of burnable poisons and neutronics characteristics of long-life PWR plate fuel assembly were studied. The transportburnup calculations of different burnable poison fuel assemblies were carried out. Some candidate BPs are selected to realize the effective control of reactivity. The results show that when the enriched isotopes ${ }^{157} \mathrm{Gd},{ }^{167} \mathrm{Er}$ and $\mathrm{B}_{4} \mathrm{C}$ are used as burnable poisons, there is almost no reactivity penalty; when PACS-J and ${ }^{231} \mathrm{~Pa}$ are used as burnable poisons, due to their own characteristics, not only does not cause reactivity penalty at end of lifetime, but also the fuel assembly life is extended, the fuel utilization rate is improved. The combination of PACS-J and the slow-burnup burnable poisons can obtain a better reactivity curve. The results of this article show that the plate fuel assemblies can be selected with enriched isotope ${ }^{157} \mathrm{Gd}$, enriched isotope ${ }^{167} \mathrm{Er}, \mathrm{B}_{4} \mathrm{C}$, ${ }^{231} \mathrm{~Pa}$ and PACS-J as burnable poisons, and the combinations of burnable poisons can be selected with two combination schemes, PACS-Er and PACS-Pa.

Keywords: long-life PWR, assembly life, combination schemes, neutronics characteristic, burnable poison

\section{INTRODUCTION}

Long-life reactor designs are currently available in the United States, Russia and other countries, such as the MIT-designed submarine reactor (Ippolito, 1990) and the Russian KLT-40 series of reactors (Gontov et al., 2019). Nuclear propulsion power reactors are an important area of pressurized water reactors (PWRs) development. Small nuclear reactor is the ideal main power units for large marine vessels due to its high power density and small size. The refueling of reactor core in marine reactors is time-consuming, expensive, and has extreme requirements for nuclear waste management and radiation protection, which can directly affect the utilization rate of nuclear marine reactors. Reducing the number of reactor core refueling during the service of such reactors can substantially improve their economic viability and reduce the amount of nuclear waste. By increasing the core fuel enrichment, the initial residual reactivity of the core is improved and the core can be operated for a longer period of time with a single fuel load. The long-life reactor 
design can reduce or eliminate the frequency of reactor refueling, allowing large marine vessels to operate for 10-20 years or more with a single fuel load.

The power level and reactor core lifetime are the crucial performance indexes of nuclear reactors. An ideal nuclear power reactor must have both long core lifetime and high power. Plate fuel has a large heat transfer area, short distance between fuel center and coolant channel, and high heat transfer efficiency (Cheng and Xiong, 2020). Lower fuel pellet and surface temperatures can be obtained at the same power level and coolant flow rate, or when the fuel pellet and surface temperature does not exceed the limit, nuclear reactors are allowed to operate at higher power. Further, plate fuel has a compact structure, which is conducive to the miniaturization of reactor core (ZCongpeiDshouhui, 1987; Song, 2013). Plate fuel is a commonly used fuel geometry for high flux research reactors and compact nuclear power reactors with high power density (Ye, 1997; Afshin et al., 2007; Gong et al., 2015; Mohamed and Mohamed, 2019). Long-life reactors based on plate fuel exhibit immense potential in applications that require both power and lifetime.

The reactor core lifetime can be enhanced by increasing the loading or conversion ratio of fissile nuclides. In pressurized water reactors (PWRs), it is difficult to achieve ultra-long reactor core lifetime by simply increasing the conversion ratio because the conversion ratio is much less than 1. Meanwhile, another challenge is that the leakage probability of the primary circuit pressure boundary increases the power distribution of reactor core and the positive temperature coefficient of moderator. Burnable poisons (BPs) has a strong capacity to absorb neutron, and the product formed after neutron absorption can either be a "transparent" nuclide or a nuclide that can continue to absorb neutron, so it has flexible residual reactivity control ability (Li et al., 2019). Therefore, BP design is a significant method to control the core residual reactivity of long-life PWR. The existing studies on the selection of burnable poisons for pressurized water reactors had been studied (Anwar and Cao, 2010; Li et al., 2019; Xu et al., 2021), but most of the current studies are based on conventional rod-shaped with low-enrichment fuel assemblies, and there are fewer studies on the selection of burnable poisons for high-enrichment plate fuel assemblies with better burnable poison neutronics characteristics. Long-life PWRs have high enrichment fuel, so long-life PWRs have large initial residual reactivity. If reactivity control is performed using traditional BPs, it may be difficult to achieve a smooth release and control of reactivity over the lifetime of a long-life PWRs.

In this study, long-life PWR plate fuel assemblies are studied. Calculations are carried out using different BPs schemes for plate fuel assemblies, and the performance of different BPs is analyzed by the variation in the $\mathrm{k}_{\text {inf }}$ of assembly containing different BPs as a function of burnup to obtain the better BPs. This study can provide a reference for the selection and design of BPs for long-life PWRs.

\section{CALCULATION PROCEDURE AND MODEL}

\section{Calculation Procedure}

The DRAGON program is used for the transport-burnup calculation. DRAGON (Marleau et al., 2016) is a deterministic

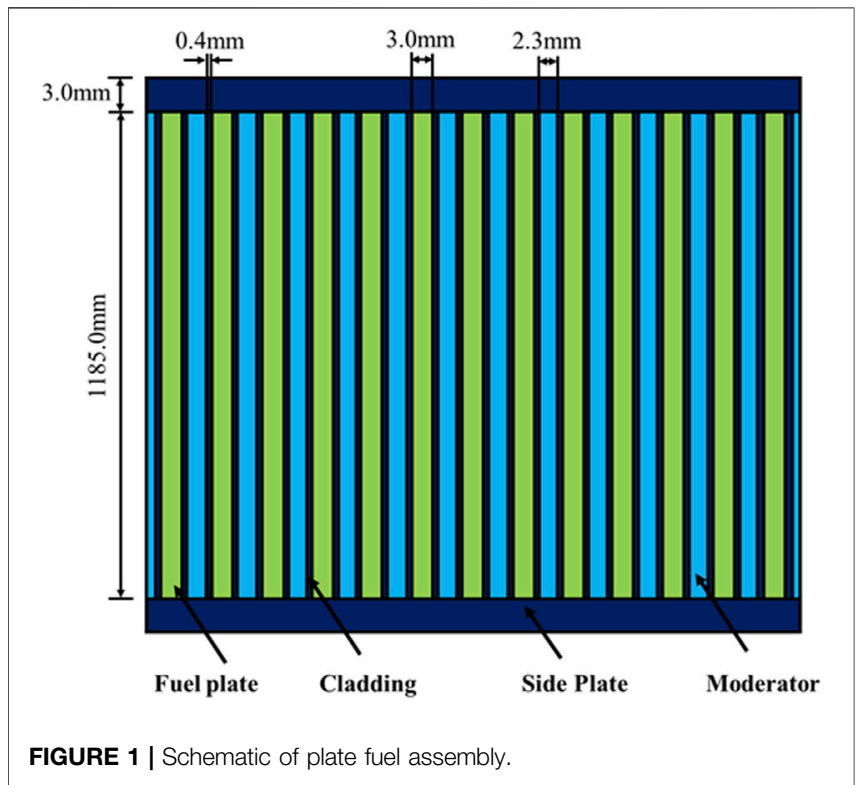

reactor lattice calculation program developed by Montreal University of Technology, Canada. Many numerical method modules can be used to solve $1 \mathrm{D} / 2 \mathrm{D} / 3 \mathrm{D}$ neutron transport problems, such as interface flow method, collision probability method, discrete ordinate method, characteristic method, and spherical harmonic function method. The DRAGON can handle fuel assemblies with different geometric structures (e.g., tube bundles, plates, hexagons) and different reactor types (e.g., light water reactor, heavy water reactor), so it has a strong geometric applicability and flexibility (Guangwen and Shengyi, 2010). The feasibility of DRAGON for plate assembly calculation has been verified (Haitao et al., 2005; Ma et al., 2015; Zhao, 2017; Yu et al., 2020). DRAGON can also perform accurate calculations for nuclides with complex burnup chains (Canbakan and Hébert, 2015; Xia et al., 2021).

There are many modules available inside the DRAGON, so in this article, the subgroup method module is chosen for resonance self-shielding calculations, the Sanchez module is chosen to handle the double non-uniformity problem, and the MOC module is chosen to handle the transport calculations. The cross section library is selected from the 172-groups WIMSD.

\section{Calculation Model}

The Schematic of plate fuel assembly is shown in Figure 1. The assembly consists of 13 fuel plates, two support plates, and water gaps $\left(\mathrm{H}_{2} \mathrm{O}\right)$, where $\mathrm{UO}_{2}$ particles, which is dispersed in the ${ }^{4} \mathrm{Zr}$ matrix, is selected as the fuel, and ${ }^{4} \mathrm{Zr}$ alloy is used as the material for the cladding, support plates, and matrix. The thicknesses of fuel core, fuel cladding, water gap between two fuel plates, the support plate, and fuel plate height are 3.0, 0.4, 2.3, 3.0, and $1,185.0 \mathrm{~mm}$, respectively. Dispersion fuel has the advantages of reasonable irradiation stability, excellent thermal conductivity, good corrosion resistance, long service life, and high burnup, thus it is widely used in long-life PWR. The enrichment of $\mathrm{UO}_{2}$ in this study is $60 \%$. The loading arrangement of BPs is as follows: the 
TABLE 1 | Calibration results.

\begin{tabular}{lccc}
\hline Program & DRAGON & Openmc & Error $(\mathbf{p c m})$ \\
\hline $\mathrm{k}_{\mathrm{inf}}$ & 1.688579 & 1.688435 & 14.4
\end{tabular}

BPs are uniformly mixed with the fuel to facilitate dispersion loading, and a symmetrical arrangement of fuel plates containing BPs is considered. To ensure the accuracy of the design, the calibration results are shown in Table 1.

\section{CANDIDATE BPs}

Unlike conventional low-enrichment rod fuel assemblies, assemblies within long-life core have higher initial reactivity. From a neutronics perspective, the selection of either natural nuclides or enriched isotopes as BPs should follow three principles: (1) BPs should suppress a large initial reactivity at beginning of lifetime; (2) BPs need to ensure a gentle release of reactivity during the lifetime; (3) Small or no reactivity penalties at end of lifetime for assemblies containing BPs allow reactors to achieve longer days of full power operation (Xie et al., 2017). In this study, the relevant physical properties of candidate BPs are evaluated in terms of suppression of initial reactivity at beginning of lifetime, reactivity released during life and reactivity penalty at end of lifetime, and BPs suitable for high enrichment long-life PWR are selected. By reducing the loading in the fuel plate, different BPs are added to make the initial value of infinite medium multiplication coefficient $\left(\mathrm{k}_{\mathrm{inf}}\right)$ as 1.20 in the assembly. Further, by changing the content of BPs in the single board and the number of BP boards in the assembly, the reactivity control requirements are satisfied and a smaller reactivity penalty is achieved finally.

Here, BP materials including non-proliferative BPs, actinide BPs, and advanced polymeric BPs are selected as the research object for the analysis.

\section{Non-proliferative BPs}

The components of non-proliferative $\mathrm{BP}$ materials are naturally abundant, and the main materials are $\mathrm{B}_{4} \mathrm{C}, \mathrm{Dy}_{2} \mathrm{O}_{3}, \mathrm{Er}_{2} \mathrm{O}_{3}, \mathrm{Eu}_{2} \mathrm{O}_{3}$, $\mathrm{Gd}_{2} \mathrm{O}_{3}$, and $\mathrm{Sm}_{2} \mathrm{O}_{3}$.

\section{Actinide BPs}

Some actinide nuclides can be converted into fissile nuclides after absorbing neutron. When these nuclides are used as BPs, they can inhibit excessive reactivity by absorbing neutron at the beginning of lifetime, and they can also use the converted fissile nuclides to prolong the life of the assembly and enhance the reactivity. Finally, it leads to a gentle variation in the residual reactivity. The actinide nuclides selected in this study are ${ }^{231} \mathrm{~Pa},{ }^{241} \mathrm{Am}$, ${ }^{237} \mathrm{NP},{ }^{238} \mathrm{Pu}$, and ${ }^{240} \mathrm{Pu}$.

\section{PACS: Advanced Polymeric BP}

Polycarboborane-siloxane-ethynyl (PACS) has good corrosion resistance and stability, thus it is an effective BP [21]. Figure 2 shows the chemical structure of PACS. In this study, two

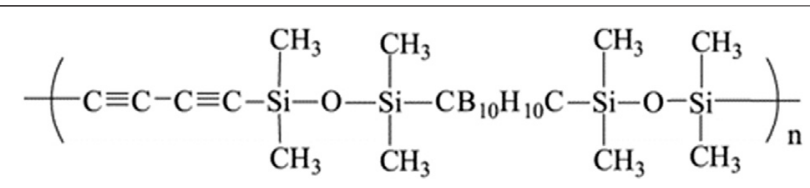

FIGURE 2 | Chemical structure of PACS.

TABLE 2 | Composition of PACS [22].

BP Density $\left(\mathrm{g} / \mathrm{cm}^{3}\right)$

\begin{tabular}{ccccc}
\multicolumn{5}{c}{ Number of atoms per molecule } \\
\hline C & H & B & O & Si \\
14 & 34 & 10 & 2 & 4 \\
44 & 84 & 10 & 5 & 12
\end{tabular}

advanced polymeric BPs: PACS-J and PACS-L (Allen et al., 2003), are selected, and their compositions are shown in Table 2.

\section{RESULTS AND ANALYSIS}

\section{Calculation Results}

The candidate BPs burnup curves are shown in Figure 3. As seen in Figure $3 \mathrm{~A}$, only ${ }^{231} \mathrm{~Pa}$ of the actinide BPs extends the life of the assembly at $\mathrm{k}_{\mathrm{inf}}=1.0$ in the case of high fuel enrichment, and all other actinide BPs showed reactive penalties of different magnitudes.

Figure 3B shows that at $\mathrm{k}_{\mathrm{inf}}=1.0$, the two advanced polymer BPs extend the life of the assembly at end of lifetime due to their own properties. At an initial $\mathrm{k}_{\mathrm{inf}}=1.20$, assemblies containing both advanced polymer BPs showed a large reactive release in the middle and late life cycle and difficulties in reactivity control. The rate of reactive release of BPs was reduced by increasing the BPs content in a single plate (increasing the BPs self-shielding effect) to slow down the rate of BPs consumption. The fuel burnup curve of PACS-L does not meet the requirements for safe reactor operation because the reactivity fluctuates widely throughout the assembly lifetime and the reactivity is more difficult to control. The reactivity fluctuation of the burnup curve of the assembly containing PACS-J did not exceed 0.2 throughout the lifetime at the initial $\mathrm{k}_{\mathrm{inf}}=1.04$, but the reactivity showed a large release in the middle and late stages of the lifetime, which prolonged the assembly lifetime but made the reactivity control difficult.

As seen in Figure 3C, the assembly containing the $\mathrm{B}_{4} \mathrm{C}$ had no reactivity penalty at end of lifetime, but the assemblies containing the other BPs all caused a reactivity penalty. The nuclides have a small absorption cross section in BPs with different natural ratios, and the nuclides produced by offspring have different absorption cross sections and half-lives. This can lead to reactivity penalty if $\mathrm{k}_{\mathrm{inf}}=1.0$. For highly enrichment assemblies, the use of natural ratios of non-proliferative BPs is not optimal.

Therefore, in this study, the natural proportion of nonproliferative $\mathrm{BPs}\left(\mathrm{Er}_{2} \mathrm{O}_{3}, \mathrm{Eu}_{2} \mathrm{O}_{3}, \mathrm{Gd}_{2} \mathrm{O}_{3}\right.$, and $\left.\mathrm{Sm}_{2} \mathrm{O}_{3}\right)$ corresponding to enriched isotope oxides $\left({ }^{167} \mathrm{Er}_{2} \mathrm{O}_{3},{ }^{151} \mathrm{Eu}_{2} \mathrm{O}_{3}\right.$, 


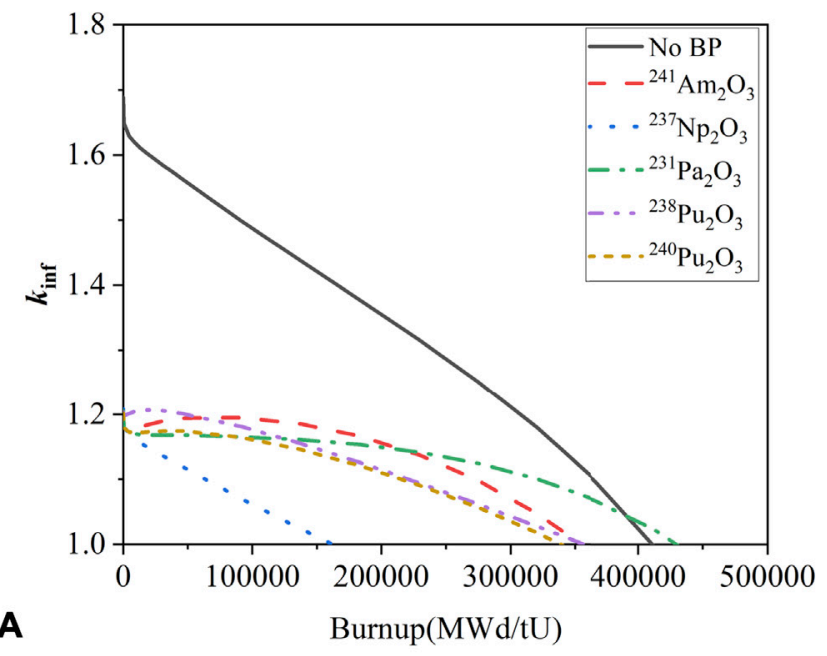

A

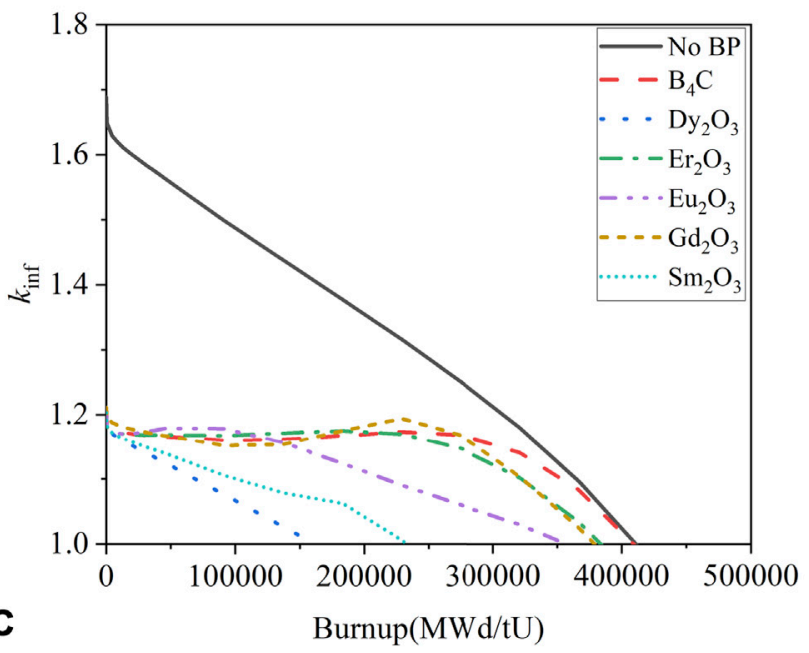

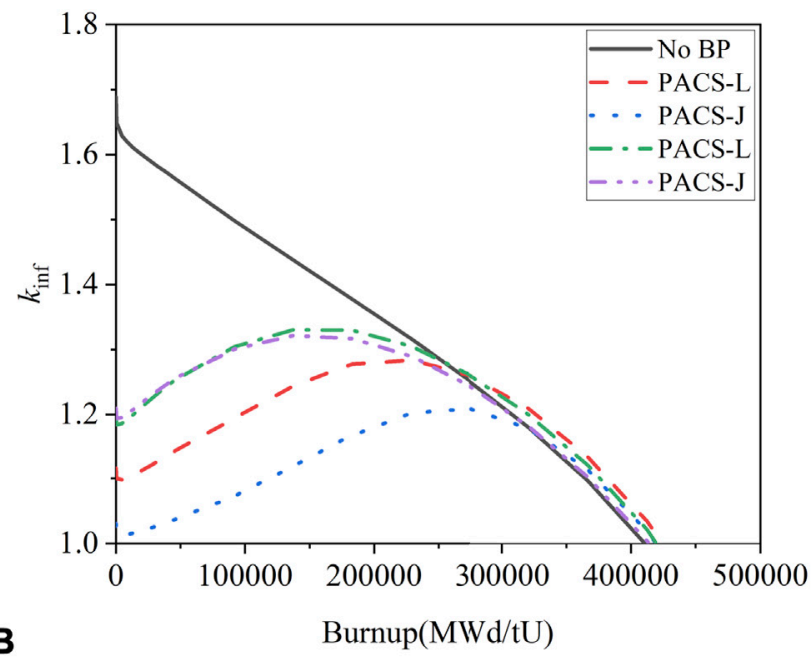

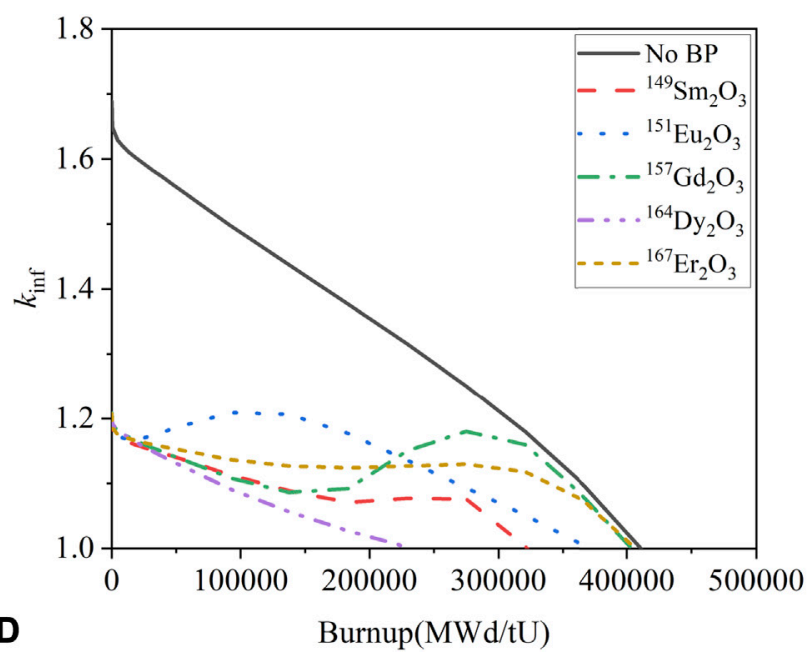

FIGURE 3 | Variation in the $\mathrm{k}_{\text {inf }}$ of assembly with different BPs schemes.

${ }^{157} \mathrm{Gd}_{2} \mathrm{O}_{3}$, and ${ }^{149} \mathrm{Sm}_{2} \mathrm{O}_{3}$ ) are selected, and all the separated isotopes are enriched at $100 \%$.As seen in Figure 3D, at high fuel enrichment, the enriched isotope is consumed more quickly as BPs, causing less reactivity penalty at end of lifetime and greater burnup of the assembly than what can be achieved with naturally proportioned BPs. The use of enriched isotopes as BPs reduces the production of daughter nuclides in the burnup chain, resulting in a reduction of some daughter nuclides with absorption cross sections, reducing the reactivity penalty at end of lifetime and improving fuel utilization.

Through the above calculations, this article conducted a selection study on different types of BPs. The results show that ${ }^{231} \mathrm{~Pa}, \mathrm{~B},{ }^{157} \mathrm{Gd},{ }^{167} \mathrm{Er}$, and PACS-J is more suitable than other BPs for long-life reactors. The reactive release of $\mathrm{B}_{4} \mathrm{C}$ and ${ }^{167} \mathrm{Er}$ as BPs was smooth throughout the burnup cycle, with no significant fluctuations throughout the life cycle and little to no reactive penalty at end of lifetime. ${ }^{157} \mathrm{Gd}$, when used as BPs, causes only a small reactivity penalty, but the reactivity is released more rapidly over the life span. When ${ }^{231} \mathrm{~Pa}$ and PACS-J are used as BPs, the lifetime of the assembly is extended beyond that of
non-BPs fuel assemblies due to ${ }^{231} \mathrm{~Pa}$ own burnup chain and PACS-J own characteristics, resulting in improved fuel utilization. However, when PACS-J is used as a single BPs, there are difficulties in lifetime reactivity control.

\section{Neutronics Characteristics Analysis of BPs}

From Calculation Rresults, it can be seen that ${ }^{231} \mathrm{~Pa}, \mathrm{~B},{ }^{157} \mathrm{Gd}$, ${ }^{167} \mathrm{Er}$ and PACS-J showed better results than other BPs. Therefore, this article performs neutronics characteristics analysis for ${ }^{231} \mathrm{~Pa}, \mathrm{~B},{ }^{157} \mathrm{Gd},{ }^{167} \mathrm{Er}$ and PACS-J.

The analysis parameters of ${ }^{231} \mathrm{~Pa}, \mathrm{~B},{ }^{157} \mathrm{Gd},{ }^{167} \mathrm{Er}$ and PACS-J are shown in Table 3. The neutron absorption cross sections for the different BPs are given in Table 3. Table 3 also contains the $\mathrm{BPs}$ content in a single plate, the number of plates in the assembly containing different BPs and the reactivity penalty at end of lifetime, which are the input parameters and results of the selection calculations performed in Calculation Rresults. In order to visualize the arrangement of fuel plates containing BPs in the assembly, Figure 4 shows the arrangement of fuel plates containing different BPs in the assembly. 
TABLE 3 | Analysis parameters for different BPs.

\begin{tabular}{ccccc}
\multicolumn{5}{c}{ Parameter values for different BPs } \\
\hline${ }^{\mathbf{1 5 7}_{\mathbf{G d}} \mathbf{G}_{\mathbf{3}}}$ & $\mathbf{B}_{\mathbf{4}} \mathbf{C}$ & ${ }^{\mathbf{1 6 7}} \mathbf{E r}_{\mathbf{2}} \mathbf{O}_{\mathbf{3}}$ & ${ }^{\mathbf{2} 1} \mathbf{P a}_{\mathbf{2}} \mathbf{O}_{\mathbf{3}}$ & PACS-J \\
253,254 & $3,838\left({ }^{10} \mathrm{~B}\right)$ & 644 & 202 & $3,838\left({ }^{10} \mathrm{~B}\right)$ \\
5.20 & 13.00 & 4.50 & 2.27 & 70.00 \\
$2,291.680$ & 458.336 & 916.672 & $-4,583.360$ & $-3,666.688$ \\
3 & 2 & 6 & 13 & 4
\end{tabular}

The neutron absorption cross section of ${ }^{157} \mathrm{Gd}$ is the largest among the selected BPs. When ${ }^{157} \mathrm{Gd}$ is used as BPs, the initial residual reactivity can be suppressed by adding only $5.20 \%$ of ${ }^{157} \mathrm{Gd}_{2} \mathrm{O}_{3}$ at beginning of lifetime, but the large absorption cross section makes the BPs consume faster, and a large reactivity release occurs in the middle and late stages of the lifetime, producing reactivity fluctuations. There is a certain neutron absorption cross section for the daughter nuclides produced by the absorption of neutrons by ${ }^{157} \mathrm{Gd}$, which causes a small reactivity penalty at end of lifetime.

The neutron absorption cross section of ${ }^{10} \mathrm{~B}$ is the largest of the two isotopes, and the burnup chain of $\mathrm{B}$ is very simple, absorbing neutrons and converting them directly to helium and lithium, which are essentially "transparent" to neutrons, with essentially no reactivity penalty at end of lifetime, but as a diffuse BPs the swelling of fuel elements due to helium release needs to be considered.

${ }^{167}$ Er has a smaller neutron absorption cross section compared to ${ }^{157} \mathrm{Gd}$, but has a certain neutron absorption cross section that burnup slower compared to ${ }^{157} \mathrm{Gd}$, reducing the BPs content in a single plate and making ${ }^{167} \mathrm{Er}_{2} \mathrm{O}_{3}$ as completely consumed as possible at end of lifetime. The daughter nuclides produced by the absorption of neutrons by ${ }^{167}$ Er have a certain neutron absorption
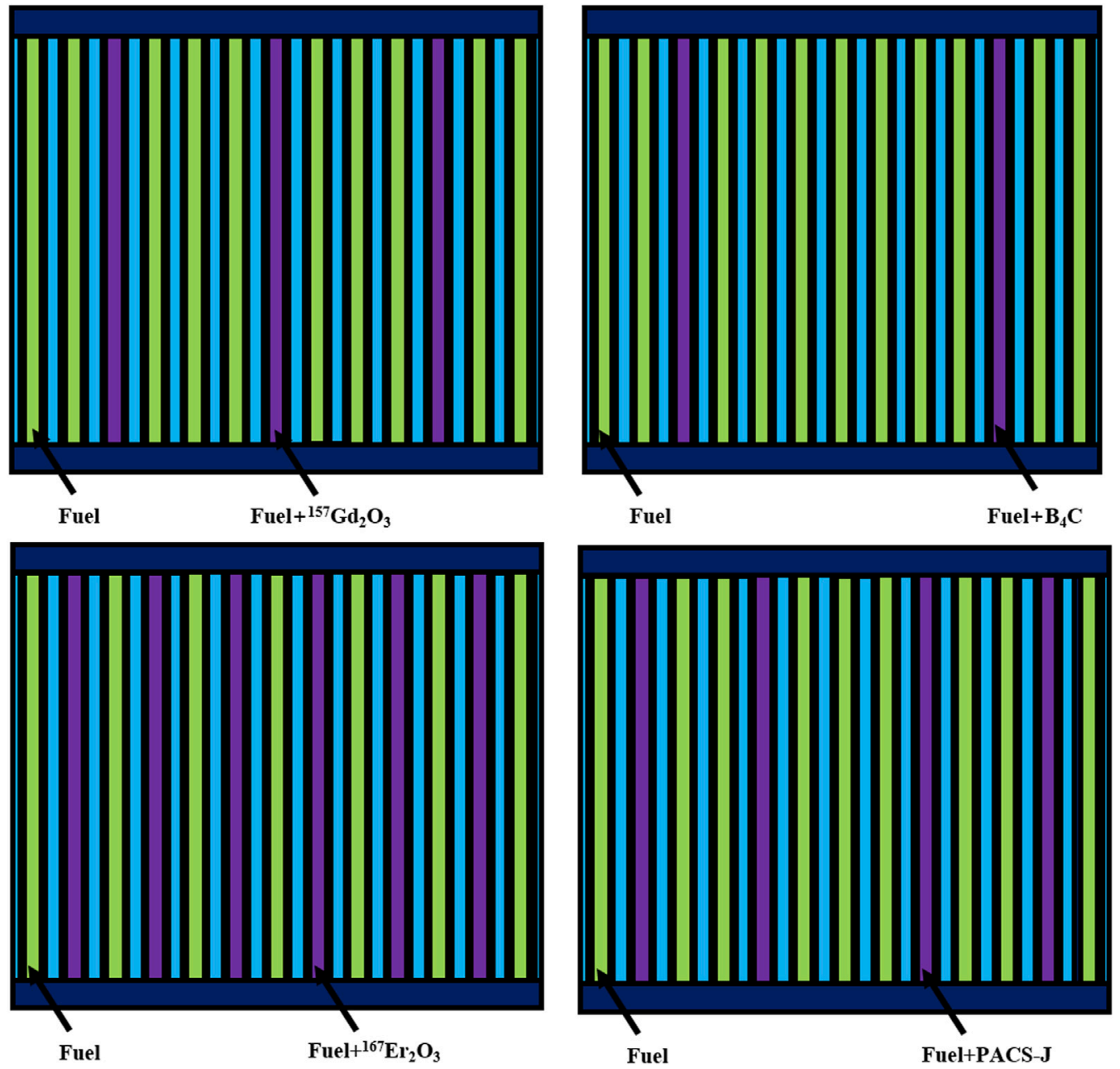

FIGURE 4 | Layout scheme of different burnable poison assemblies. 


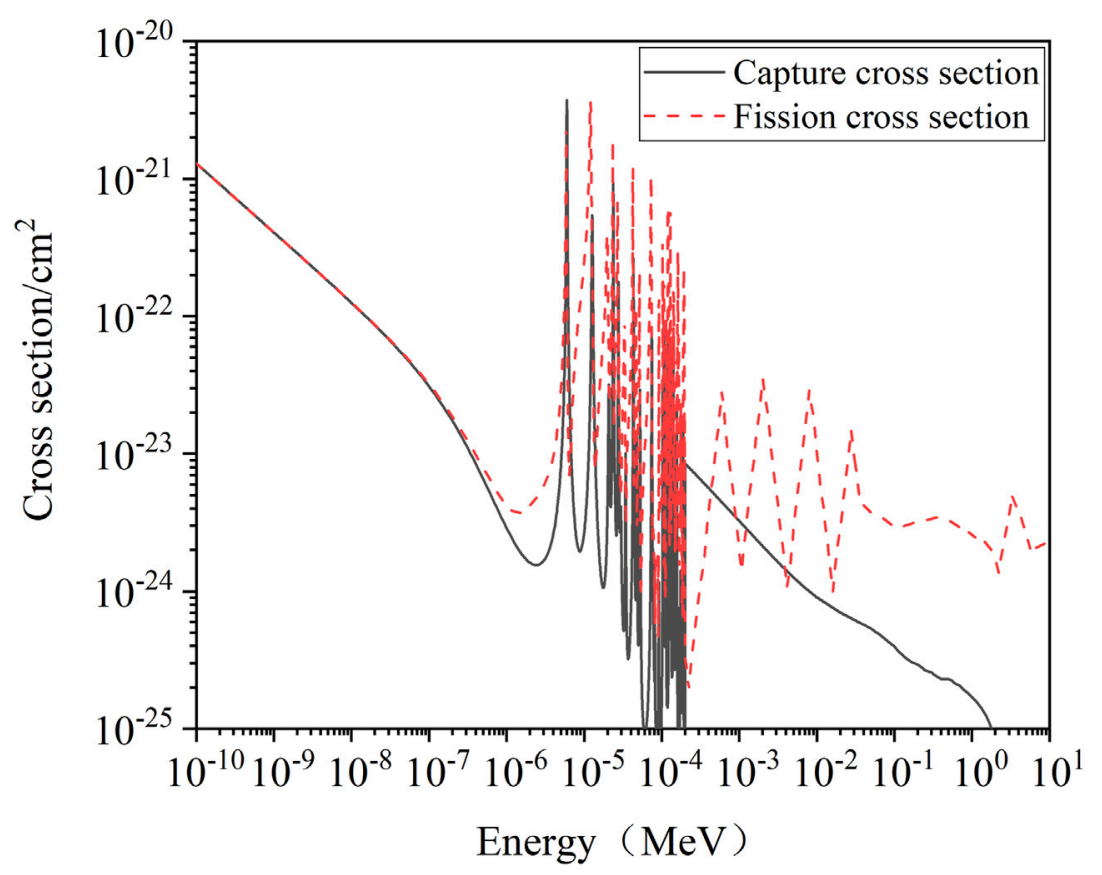

FIGURE 5 | Capture and fission cross sections of ${ }^{232} U$.

cross section, which causes a small reactivity penalty at end of lifetime.

The neutron absorption cross section of ${ }^{231} \mathrm{~Pa}$ is relatively small compared to ${ }^{157} \mathrm{Gd}$ and ${ }^{167} \mathrm{Er}$, so the burnup rate is significantly slower and better control of reactivity can be achieved. The burnup chain of ${ }^{231} \mathrm{~Pa}$ is different from the other nuclides (Kulikov et al., 2017). ${ }^{231} \mathrm{~Pa}$ acts as the parent nucleus of this burnup chain, and fissionable ${ }^{232} U$ and ${ }^{233} U$ exist directly in the burnup chain. ${ }^{232} \mathrm{~Pa}$ is generated after the capture of neutrons by ${ }^{231} \mathrm{~Pa}$, and ${ }^{232} \mathrm{~Pa}$ has a half-life of only 1.3 days and decays to form ${ }^{232} \mathrm{U}$. The fission and capture cross sections of ${ }^{232} \mathrm{U}$ are very similar, which allows ${ }^{232} \mathrm{U}$ to both capture neutrons to produce the fissile nuclide ${ }^{233} \mathrm{U}$ and to fission directly to supplement reactivity. The capture and fission cross section of ${ }^{232} \mathrm{U}$ is shown in Figure 5. The special burnup chain of ${ }^{231} \mathrm{~Pa}$ offers the possibility to achieve high burnup with ${ }^{231} \mathrm{~Pa}$ assemblies.

PACS-J has a high hydrogen content and high boron content, and its high hydrogen content makes PACS-J have its own slowing effect as BPs, which can better slow down neutrons at end of lifetime, improve thermal neutron utilization, and promote the consumption of fission nuclide $\mathrm{Pu}$. Therefore, PACS-J can extend the burnup and improve fuel utilization at end of lifetime when used as BPs.

From the above neutronics characteristics analysis, it is known that the main neutron absorber in PACS-J is ${ }^{10} \mathrm{~B}$, and the absorption cross section of ${ }^{10} \mathrm{~B}$ is 3,838 barn.Because the higher fuel enrichment makes the life time initial reactivity larger, when PACS-J is used as a single BP for reaction control, although increasing the content (70\%) of BP in a single plate to increase the self-shielding effect, the assembly reactivity fluctuation is still the largest among the selected BPs. Therefore, in the case of high fuel enrichment, PACS-J can be considered in combination with BPs with small neutron absorption cross section (slow-burnup).

\section{COMBINATION OF BPs}

In this article, a preliminary study of BPs combinations was conducted without changing the BPs content in a single plate and only adjusting the number of BPs plates containing PACS-J, ${ }^{167} \mathrm{Er}_{2} \mathrm{O}_{3}$ and ${ }^{231} \mathrm{~Pa}_{2} \mathrm{O}_{3}$ in the assemblies.

For the combination of PACS-J and ${ }^{167} \mathrm{Er}_{2} \mathrm{O}_{3}$, the number of BPs plates containing PACS-J and ${ }^{167} \mathrm{Er}_{2} \mathrm{O}_{3}$ is 1 and 4, respectively, and the others are pure fuel plate elements. For the combination of PACS- $J$ and ${ }^{231} \mathrm{~Pa}_{2} \mathrm{O}_{3}$, the number of BPs plates containing PACS-J and ${ }^{231} \mathrm{~Pa}_{2} \mathrm{O}_{3}$ is 1 and 10 , respectively, and the others are pure fuel plate elements. The schematic diagram of the assemblies arrangement is shown in Figure 6.

Figure 7 shows the burnup curves of PACS-J combined with ${ }^{167} \mathrm{Er}_{2} \mathrm{O}_{3}$ and ${ }^{231} \mathrm{~Pa}_{2} \mathrm{O}_{3}$. It can be seen that the initial $\mathrm{k}_{\text {inf }}$ of the assembly is about 1.10 after the combination of PACS-J with BPs of small neutron absorption cross section, and there is no large fluctuation in the reactivity of assemblies throughout the lifetime, and the reactivity is released smoothly during the lifetime. There was no reactivity penalty at the end of life and the lifetime was extended by $2,750.016 \mathrm{MWd} / \mathrm{tU}$ at end of lifetime for the PACSEr combination and 9,625.056 $\mathrm{MWd} / \mathrm{tU}$ for the PACS-Pa combination. The reactivity fluctuations for both BPs combination scenarios were about 0.1 over the entire lifetime.

PACS-J has a large neutron absorption cross section as BPs, and because the assemblies has a large initial reactivity, if single 

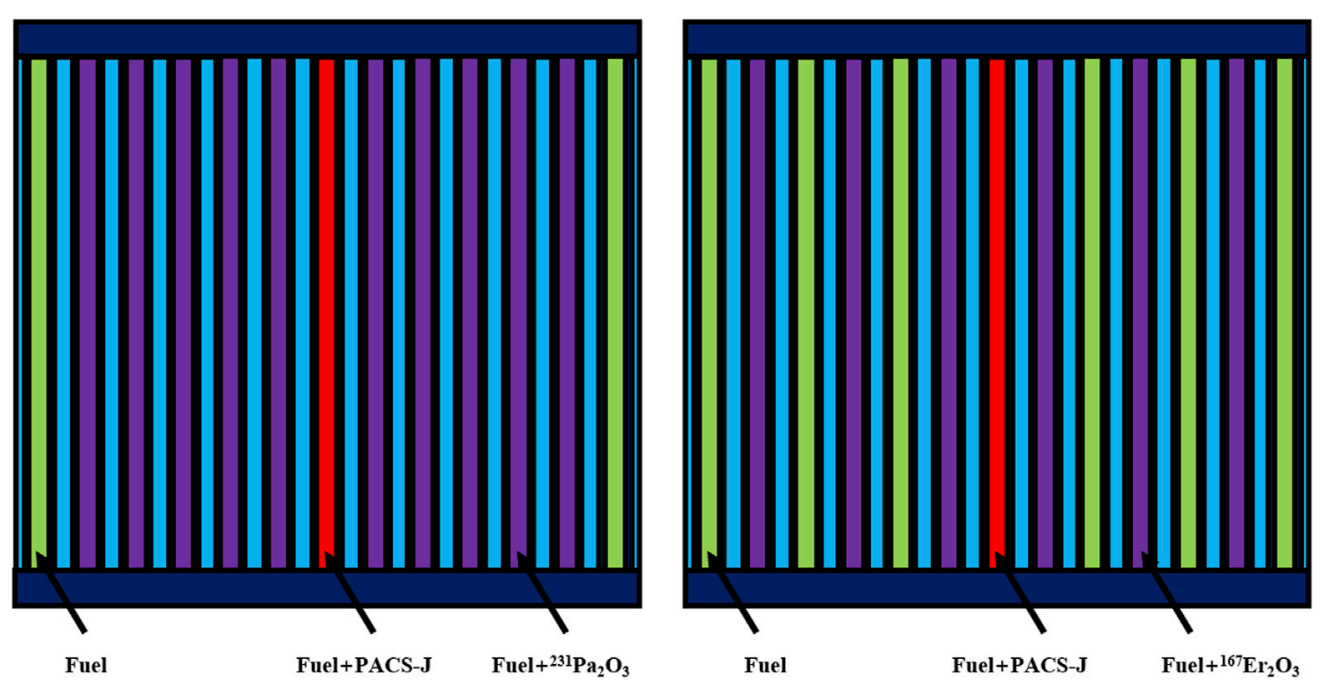

FIGURE 6 | Layout scheme of assembly with different numbers of burnable poisons.

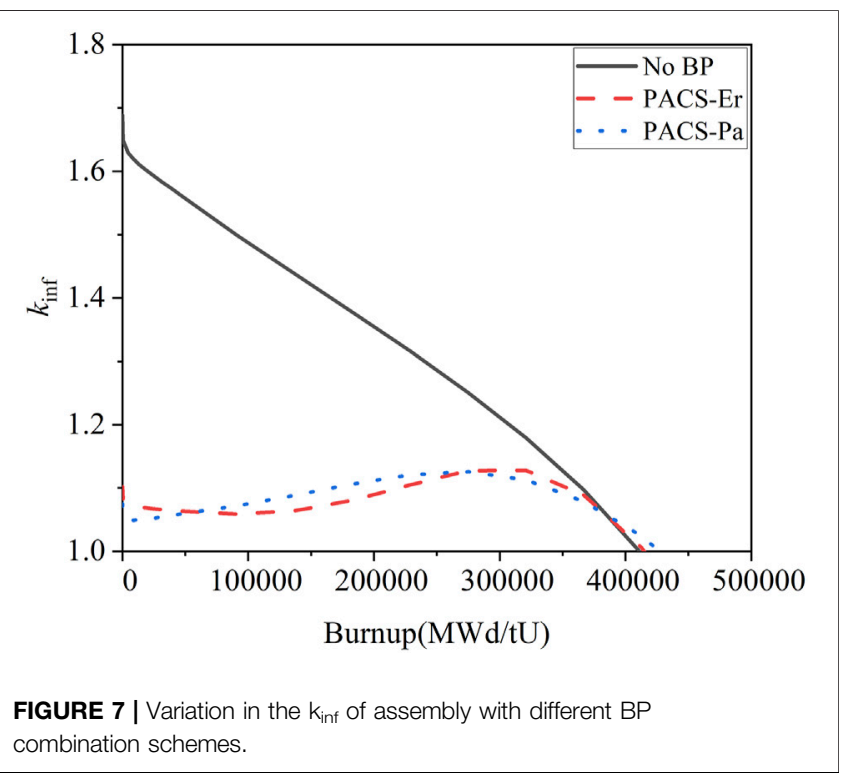

BPs with a large neutron absorption cross section is used for reactivity control, the initial residual reactivity can be suppressed at beginning of lifetime. However, as the burnup deepens, the reactivity is released more quickly and the assemblies show large reactivity fluctuations. The combination of "fast-burnup" BPs with "slow-burnup" BPs can compensate the disadvantage of difficult assembly reactivity control at high enrichment, thus obtaining better reactive burnup curve.

\section{CONCLUSION}

In this study, based on high enrichment plate fuel assemblies, BPs selection and neutronics characterization studies are carried out, transport-burnup calculations are performed for different BPs, and BPs with better neutronics performance are selected. The specific conclusions are as follows:

1) For plate fuel assemblies, oxides of ${ }^{157} \mathrm{Gd}$ and ${ }^{167} \mathrm{Er}$ in enriched isotopes can be used as BPs to reduce the reactivity penalty at end of lifetime; there is almost no reactivity penalty at end of lifetime when $\mathrm{B}_{4} \mathrm{C}$ is used as BPs. Also ${ }^{231} \mathrm{~Pa}$ and PACS-J, when used as BPs, both extend the assemblies burnup at end of lifetime and improve fuel utilization. The ${ }^{157} \mathrm{Gd},{ }^{167} \mathrm{Er},{ }^{231} \mathrm{~Pa}$ and PACS-J can be used as candidates for long-life PWRs when they are obtained economically.

2) At high fuel enrichment, some of the "fast-burnup" BPs are not suitable for reactive control as a single BPs in the assembly, but a better reactive burnup curve can be obtained by a reasonable combination with "slow-burnup" BPs. For example, PACS can be combined with "slow-burnup" BPs Er and $\mathrm{Pa}$ to increase the control of reactivity.

\section{DATA AVAILABILITY STATEMENT}

The raw data supporting the conclusions of this article will be made available by the authors, without undue reservation.

\section{AUTHOR CONTRIBUTIONS}

SX designed the Scheme and performed simulations, analyzed data, and drafted or provided the revision of the article. TY, JX, LY participated in the work and co-wrote the article. ZL supervised the research and resolved appropriately, provided the revision of the article, and approved of the final version to be published. All authors contributed to the article and approved the submitted version. 


\section{FUNDING}

This study is supported by the science and technology innovation Program of Hunnan Province (Nos.2020RC4053) and National Natural Science Foundation of China (No. 11875162).

\section{REFERENCES}

Afshin, H., Hadi, D., and Jalil, J. (2007). Loss of Coolant Accident Analyses on Tehran Research Reactor by RELAP5/MOD3.2 Code[J]. Prog. Nucl. Energ. 49 (7), 511-528.

Allen, K., Baney, R., and Butt, D. (2003). An Advanced Burnable Poison for Pressurized Water Reactors[C]. Proc. Conf. Adv. Nucl. Fuel Manag., 5-8.

Anwar, H., and Cao, X. (2010). Small PWR Core Design with Coated Particle Based Fuel with a Novel Composition[J]. Prog. Nucl. Energ. 52 (6), 531-535.

Canbakan, A., and Hébert, A. (2015). Accuracy of a 2-level Scheme Based on a Subgroup Method for Pressurized Water Reactor Fuel Assembly Models. Ann. Nucl. Energ. 81, 164-173. doi:10.1016/j.anucene.2015.03.034

Cheng, R., and Xiong, J. (2020). Numerical Analysis of Flow Blockage Accidents in Inlet of Plate-type Fuel Assembly[J]. Nucl. Power Eng. 41 (S2), 92-97.

Congpei, Z., and Shouhui, D. (1987). UO2 Ceramic Plate Fuel Assembly[J]. Nucl. Power Eng. 8 (1), 74-78, 88.

Gong, D., Huang, S., Wang, G., and Wang, K. (2015). Heat Transfer Calculation on Plate-type Fuel Assembly of High Flux Research Reactor. Sci. Tech. Nucl. Installations 2015, 1-13. doi:10.1155/2015/198654

Gontov, V. S., Anikin, N. A., and Chernov, L. V. The Study of the Probability of Increasing the Operating Time of the Nuclear Reactor KLT-40 S through the Use of Perspective Nuclear Fuel Cycles[C]//Физикоќтечнические Шроблемы В Наукењ Шромышленности И Медицине ЋФТШНШМќЫЩъыЏь Сборник Научныч трудов Международной НаучноќШрактической конференции Студентовњ асШирантов И Молодыч ученычњ Гћ Томскњ ЬЩ СентябряќщЭ октября ЫЩЪы ГћТомскњ ЫЩЪыћ ЫЩЪыь ЬЬЬЭћ

Guangwen, B., and Shengyi, S. (2010). "Validation and Analysis of the DRAGON Program for Pressurized Water Reactor Fuel Assembly Calculations [C],” in The 13th Reactor Numerical Calculation and Particle Transport Conference and 2010 Reactor Physics Conference. Chinese Nuclear Society.

Haitao, J., Hongchun, W., and Dong, Y.. Computer Simulation of Variform Fuel Assemblies Using Dragon Code[C]. In 13th International Conference on Nuclear Engineering. 2005.

Ippolito, T. D. (1990). Effects of Variation of Uranium Enrichment on Nuclear Submarine Reactor Design[D]. Mass. Inst. Tech.

Kulikov, G. G., Kulikov, E. G., Shmelev, A. N., and Apse, V. A. (2017). Protactinium-231 - New Burnable Neutron Absorber. Nucl. Energ. Tech. 3 (4), 255-259. doi:10.1016/j.nucet.2017.10.002

Li, M., Yu, Y., and Xiao, P. (2019). Nuetronic Analysis on Separated Isotope Burnable Poisons for Long-Life Reactor Core[J]. Sci. Tech. Nucl. Installations 40 (S2), 74-77. doi:10.1155/2015/198654

\section{ACKNOWLEDGMENTS}

The authors would like to show their great appreciations to NEAL (Nuclear Engineering and Application Laboratory) Team for its contribution to this research.

Ma, J., Wang, G., and Yuan, S. (2015). An Improved Assembly Homogenization Approach for Plate-type Research Reactor[J]. Ann. Nucl. Energ. 85, 1003-1013. doi:10.1016/j.anucene.2015.07.018

Marleau, G., Hebert, A., and Roy, R. (2016). A User Guide for DRAGON Version4, Report IGE-294[R]. Canada: Ecole Polytechnique de Montreal.

Mohamed, A. G., and Mohamed, A. (2019). Analysis of Natural Circulation loop in MTRs Using CONVEC Code[J]. Prog. Nucl. Energ. 117, 110-114.

Renier, J. A. (2003). Development of Improved Burnable Poisons for Commercial Nuclear Power Reactors. Final Report on NERI project Number 99-0074[J]. US: Department of Energy.

Song, L. (2013). Numerical Analysis of Flow Blockage Accident of Plate Fuel Assembly[D]. Harbin Eng. Univ.

Xia, Y., Xie, J., and Xu, S. (2021). Neutronic Design and Analysis of Dispersed Particle Burnable Poison for Long Cycle PWR[J/OL]. At. Energ. Sci. Tech. 1-8, 2021 available at: http://kns.cnki.net/kcms/detail/11.2044.TL.20210317.1611.012. html.

Xie, M., Chen, Y., and Lei, Y. (2017). Analysis for Burnup Characteristics of Advanced Polymeric Burnable Poison[J]. Nucl. Sci. Eng. 37 (2), 320-326.

$\mathrm{Xu}, \mathrm{S}$., Yu, T., and Xie, J. (2021). Burnable Poison to Improve Life of UO2 Fuel Small PWR Core[J]. At. Energ. Sci. Tech. 55 (2), 265-271.

Ye, C. (1997). China Advanced Research Reactor (CARR): A New Reactor to Be Built in China for Neutron Scattering Studies. Physica B: Condensed Matter 241-243, 48-49. doi:10.1016/s0921-4526(97)00509-7

Yu, T., Liu, J., and Xie, J. (2020). Study on Burnup Characteristics of Actinide Burnable Poisons in Plate-type Fuel Assembly[J]. Nucl. Power Eng. 41 (03), 1-7.

Zhao, W. (2017). Study of TRU Transmutation and Th-U Proliferation Characteristics in Molten Salt Stacks [D]. Hengyang: University of South China.

Conflict of Interest: The authors declare that the research was conducted in the absence of any commercial or financial relationships that could be construed as a potential conflict of interest.

Publisher's Note: All claims expressed in this article are solely those of the authors and do not necessarily represent those of their affiliated organizations, or those of the publisher, the editors and the reviewers. Any product that may be evaluated in this article, or claim that may be made by its manufacturer, is not guaranteed or endorsed by the publisher.

Copyright (C) $2021 \mathrm{Xu}, \mathrm{Yu}, \mathrm{Xie}, \mathrm{Yao}$ and Li. This is an open-access article distributed under the terms of the Creative Commons Attribution License (CC BY). The use, distribution or reproduction in other forums is permitted, provided the original author(s) and the copyright owner(s) are credited and that the original publication in this journal is cited, in accordance with accepted academic practice. No use, distribution or reproduction is permitted which does not comply with these terms. 